\title{
Incidence and management of mandibular fractures in a low-resource health facility in Ghana
}

\author{
Paul Frimpong ${ }^{1}$, Truc Thi Hoang Nguyen ${ }^{3}$, Buyanbileg Sodnom-Ish ${ }^{3}$, Edinam Salia Nimatu', \\ Nana Yaa Asantewaa Dampare ${ }^{1}$, Roberta Rockson ${ }^{1}$, Samuel Baffour Awuah, \\ Emmanuel Kofi Amponsah", Cardinal Newton ${ }^{2}$, Soung Min Kim ${ }^{1,3}$ \\ ${ }^{1}$ Oral and Maxillofacial Microvascular Reconstruction LAB, ${ }^{2}$ Department of Restorative Dentistry, Brong Ahafo Regional Hospital, Sunyani, Ghana, \\ ${ }^{3}$ Department of Oral and Maxillofacial Surgery, Dental Research Institute, School of Dentistry, Seoul National University, Seoul, Korea
}

\begin{abstract}
J Korean Assoc Oral Maxillofac Surg 2021;47:432-437)
Objectives: The mandible and other parts of the maxillofacial region suffer significant morbid injuries following road traffic accidents. Our study gives epidemiological description of mandibular fractures in Ghana and also evaluates the relevance of closed reduction and indirect fixation for managing mandibular fractures in low-resource health facilities in low-income countries like Ghana.

Patients and Methods: This is a retrospective study involving 268 patients who reported to the Department of Oral and Maxillofacial Surgery of the Sunyani Regional Hospital with mandibular fractures from January 2010 to December 2019. Patient medical records were assessed for information on age, sex, fracture etiology, anatomic location of fracture, time of day of road traffic accident, and other associated injuries.

Results: A total of 268 patients were included in this study (males, 216 [80.6\%]; females, 52 [19.4\%]). Motor vehicular accident (MVA) was the leading cause of mandibular fractures (202 injuries, 75.4\%). Other etiologies included assault (39, 14.6\%), gunshot (13, 4.9\%), falls (12, 4.5\%), and industrial accidents (2, 0.7\%). Of the 161 male cases caused by MVA, 121 (75.2\%) occurred at night and in the evening while the remaining $40(24.8 \%)$ occurred in the morning and afternoon. Among all managed 222 patients, 212 (79.1\%) were treated with closed reduction and indirect fixation technique while $10(3.7 \%)$ were treated with open reduction and direct fixation.

Conclusion: Closed reduction with indirect fixation could successfully be used to manage mandibular fractures in low resourced health facilities, especially in low-income countries. The poor lightening system on roads in Ghana is a major contributory factor to motor vehicular accidents.
\end{abstract}

Key words: Mandibular fracture, Closed fracture reduction, Motor vehicular accident, Poor lightening

[paper submitted 2020. 11. 13 / revised 1st 2020. 12. 25, 2nd 2021. 1. 14 / accepted 2021. 1. 21]

\section{Introduction}

The mandible is a prominent bone in the maxillofacial region; thus, injuries to this bone tend to occur at higher rates than other areas of the body ${ }^{1-3}$. Motor vehicular accident (MVA) is the leading cause of mandibular fractures in lowincome countries, while interpersonal violence is the leading cause in high-income countries ${ }^{2}$. Reckless driving, non-

\section{Soung Min Kim}

Department of Oral and Maxillofacial Surgery, Dental Research Institute, School of Dentistry, Seoul National University, 101 Daehak-ro, Jongno-gu, Seoul 03080, Korea

TEL: +82-2-2072-0213

E-mail:smin5@snu.ac.kr

ORCID: https://orcid.org/0000-0002-6916-0489

(c) This is an open-access article distributed under the terms of the Creative Commons Attribution Non-Commercial License (http://creativecommons.org/ licenses/by-nc/4.0/), which permits unrestricted non-commercial use, distribution, and reproduction in any medium, provided the original work is properly cited.

Copyright (C) 2021 The Korean Association of Oral and Maxillofacial Surgeons. adherence to road safety regulation and poor road conditions are some of the major factors leading to MVA in developing countries like Ghana. Mandibular fracture, which can occur solitarily or in combination with other facial and skeletal injuries is also frequently caused by assault, industrial accidents, contact sports, falls, and firearm injuries.

The Department of Oral and Maxillofacial Surgery at the Sunyani Regional Hospital, which has a bed capacity of 450, supports the medical needs of the middle, northwestern, and northern belts of Ghana. This is the only accredited center in the middle and northern regions of Ghana. It thus receives referrals from five regions of Ghana as well as from eastern Cote d'Ivoire.

The objectives of this study were to describe the epidemiology of the mandibular fractures in Ghana and to evaluate the efficacy of closed reduction and indirect fixation techniques to successfully manage mandibular fractures in a low- 
resource health facility. Additionally, we tested the prediction that poor lightening systems for roads at night in Ghana contribute disproportionately to MVAs.

\section{Patients and Methods}

\section{Patient data}

This retrospective study included data collected from 268 patients who reported to the Department of Oral and Maxillofacial Surgery at the Sunyani Regional Hospital with mandibular fractures from January 2010 to December 2019. Patients' medical records were assessed for information on age, sex, fracture etiology, anatomical location of fracture, time of day of road traffic accident, and other associated injuries. Patients who had incomplete records, suffered severe systemic or multi-organ injuries, were discharged against medical advice, or were referred to a tertiary center for further management were excluded from this study. The study protocol and access to patient records were approved by the Institutional Review Board of Seoul National University (S-D20200021), and the informed consent was waived by the IRB.

\section{Statistical analyses}

The data were entered into Microsoft Excel 2010 (Micro-

Table 1. Age and sex distribution in our study population

\begin{tabular}{cccc}
\hline Age group & Male & Female & Total \\
\hline $1-10$ & $6(2.8)$ & $2(3.8)$ & $8(3.0)$ \\
$11-20$ & $11(5.1)$ & $3(5.8)$ & $14(5.2)$ \\
$21-30$ & $99(45.8)$ & $32(61.5)$ & $131(48.9)$ \\
$31-40$ & $65(30.1)$ & $4(7.7)$ & $69(25.7)$ \\
$41-50$ & $19(8.8)$ & $9(17.3)$ & $28(10.4)$ \\
$51-60$ & $16(7.4)$ & $2(3.8)$ & $18(6.7)$ \\
Total & 216 & 52 & 268 \\
\hline
\end{tabular}

Values are presented as number (\%).

Paul Frimpong et al: Incidence and management of mandibular fractures in a lowresource health facility in Ghana. J Korean Assoc Oral Maxillofac Surg 2021

Table 2. Distribution of subjects according to etiology

\begin{tabular}{lccc}
\hline \multicolumn{1}{c}{ Etiology } & Male & Female & Total \\
\hline $\begin{array}{l}\text { Motor vehicular } \\
\text { accident }\end{array}$ & $161(74.5)$ & $41(78.8)$ & $202(75.4)$ \\
Assault & $36(16.7)$ & $3(5.8)$ & $39(14.6)$ \\
Gunshot & $11(5.1)$ & $2(3.8)$ & $13(4.9)$ \\
Falls & $6(2.8)$ & $6(11.5)$ & $12(4.5)$ \\
Industrial & $2(0.9)$ & 0 & $2(0.7)$ \\
Total & 216 & 52 & 268
\end{tabular}

Values are presented as number (\%).

Paul Frimpong et al: Incidence and management of mandibular fractures in a lowresource health facility in Ghana. J Korean Assoc Oral Maxillofac Surg 2021 soft, Redmond, WA, USA) and analyzed with simple descriptive statistics using SPSS (ver. 15; SPSS, Chicago, IL, USA).

\section{Results}

A total of 268 patients were included in this study (males, 216 [80.6\%], females, 52 [19.4\%]). The male-to-female ratio was $4.2: 1$, and ages ranged from 2 to 59 years with a mean age of 28.6 years.(Table 1) MVA was the leading cause of mandibular fractures, accounting for $202(75.4 \%)$ of all injuries. Other etiologies were assault $(n=39,14.6 \%)$, gunshot $(\mathrm{n}=13,4.9 \%)$, falls $(\mathrm{n}=12,4.5 \%)$, and industrial accident $(\mathrm{n}=2,0.7 \%)$.(Table 2$)$

Ninety of the 161 male MVA cases (55.9\%) occurred at night (9 p.m. to 6 a.m.) and 31 (19.3\%) occurred in the evening (4 p.m. to 9 p.m.). The remaining MVAs occurred in the morning $(n=24,14.9 \%)$ and afternoon $(n=16,9.9 \%)$.(Table 3$)$

A total of 325 mandibular fractures were recorded in 268 patients with an average of 1.2 fractures per patient: 168 patients (62.7\%) had a single fracture line, 89 (33.2\%) had double fracture lines, and $11(4.1 \%)$ had more than two fracture lines. Mandibular fractures involving the parasymphyseal region ( $\mathrm{n}=121)$ were the most common fracture line recorded in this study, followed by fractures in the body of mandible $(n=87)$ and the condyle $(n=56)$. Other fracture types recorded in this study involved the angle ( $\mathrm{n}=26)$, symphysis $(\mathrm{n}=22)$, ramus ( $\mathrm{n}=11)$, and coronoid $(\mathrm{n}=2)$. (Table 4$)$

The most common multiple mandibular fracture recorded in this study involved the parasymphysis and the body, fol-

Table 3. Distribution of motor vehicular accident cases based on the time of the day

\begin{tabular}{lc}
\hline \multicolumn{1}{c}{ Time of the day } & No. of cases (\%) \\
\hline Morning (6 a.m. to 12 p.m.) & $24(14.9)$ \\
Afternoon (12 p.m. to 4 p.m.) & $16(9.9)$ \\
Evening (4 p.m. to 9 p.m.) & $31(19.3)$ \\
Night (9 p.m. to 6 a.m.) & $90(55.9)$ \\
\hline
\end{tabular}

Paul Frimpong et al: Incidence and management of mandibular fractures in a lowresource health facility in Ghana. J Korean Assoc Oral Maxillofac Surg 2021

Table 4. Distribution of fractures based on anatomic location

\begin{tabular}{lc}
\hline \multicolumn{1}{c}{ Site } & No. of cases $(\%)$ \\
\hline Parasymphysis & $121(37.2)$ \\
Body & $87(26.8)$ \\
Condyle & $56(17.2)$ \\
Angle & $26(8.0)$ \\
Symphysis & $22(6.8)$ \\
Ramus & $11(3.4)$ \\
Coronoid & $2(0.6)$ \\
\hline
\end{tabular}

Paul Frimpong et al: Incidence and management of mandibular fractures in a lowresource health facility in Ghana. J Korean Assoc Oral Maxillofac Surg 2021 
lowed by the parasymphysis and the condyle. Associated injuries recorded in our study were distributed as follows: head injury $(n=76)$, depressed skull fracture $(n=13)$, Le Fort I ( $\mathrm{n}=23)$, Le Fort II $(\mathrm{n}=14)$, Le Fort III $(\mathrm{n}=3)$, zygomatic fracture $(n=17)$, frontal bone fracture $(n=4)$, nasal bone fracture $(n=7)$, ulna fracture $(n=5)$, radius fracture $(n=4)$, fibula fracture $(n=10)$, cervical injury $(n=13)$, and rib fracture $(n=2)$. (Table 5)

Total 222 cases were managed, and 212 cases (79.1\%) were treated using closed reduction and indirect fixation techniques. Of these, $176(65.7 \%)$ were treated with intermaxillary fixation using Erich arch bars, 28 (10.4\%) were treated with direct dental wiring eyelet, and $8(3.0 \%)$ were treated using acrylic cap splint with circummandibular wiring. Fig. 1 shows a pictorial description of a 36 year old with bilateral mandibular fracture treated using closed reduction and indirect fixation using Erich arch bars.

Few patients $(\mathrm{n}=10,3.7 \%)$ were treated with open reduction and direct fixation, but of these, 3 received monocortical miniplates and 7 received transosseous wiring. Fifteen (5.6\%)

Table 5. Associated injuries recorded in our study population

\begin{tabular}{lc}
\hline \multicolumn{1}{c}{ Injury type } & No. of cases $(\%)$ \\
\hline Head injury & $76(39.8)$ \\
Depressed skull fracture & $13(6.8)$ \\
Le Fort I & $23(12.0)$ \\
Le Fort II & $14(7.3)$ \\
Le Fort III & $3(1.6)$ \\
Zygomatic fracture & $17(8.9)$ \\
Frontal bone fracture & $4(2.1)$ \\
Nasal bone fracture & $7(3.7)$ \\
Ulna fracture & $5(2.6)$ \\
Radius fracture & $4(2.1)$ \\
Fibula fracture & $10(5.2)$ \\
Cervical injury & $13(6.8)$ \\
Rib fracture & $2(1.0)$ \\
Total & $191(100)$ \\
\hline
\end{tabular}

Paul Frimpong et al: Incidence and management of mandibular fractures in a lowresource health facility in Ghana. J Korean Assoc Oral Maxillofac Surg 2021 patients who presented with undisplaced condylar fracture with acceptable occlusion were managed conservatively and kept on a soft diet with periodic monitoring. Twenty-five (9.3\%) patients were referred to a tertiary health facility due to other serious associated injuries that required urgent care that could not be provided at our facility. Six patients were discharged against medical advice.

\section{Discussion}

Maxillofacial injuries continue to generate discussion among researchers globally. The mandible is the second most commonly fractured part of the maxillofacial skeleton because of its position and prominence. Fracture location and pattern are determined by injury mechanism and direction of the force vector ${ }^{4}$. Additionally, the patient's age, presence of teeth, and the physical properties of the causing agent also directly affect the characteristics of the resulting injury. The mandible is the heaviest and strongest facial bone but is prone to fractures because it is an open arch, is located in the lower portion of the face, and atrophies during the aging process $^{4,5}$. This study retrospectively evaluated 268 patients with mandibular fractures over an 8-year period from January 2010 to December 2019. In many countries, mandible fractures are reported significantly more often than middle-third facial fractures ${ }^{6-9}$.

In this study, people of all ages and gender were affected by mandibular fracture, but patients in their 20 s had the highest fracture rates. About $48.9 \%$ of fracture patients in this study were 21-30 years old. This incidence is similar to estimates by Ragupathy and Pasupathy ${ }^{10}$. This could be because people in this age range are in the most active period of life and may be exposed to more dangerous situations that are more likely to result in accidents. The incidence was higher in males (4.2:1), which agrees with previous studies that esti-
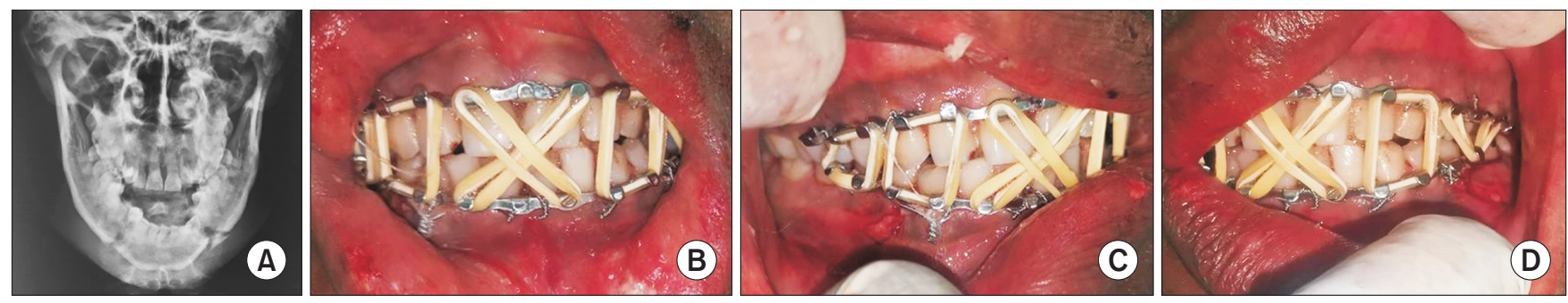

Fig. 1. A pictorial description of a 36-year-old male patient with bilateral mandibular fracture treated using closed reduction and indirect fixation using Erich arch bars, modified Town's view (A), closed reduction state with rubber boxing including frontal $(B)$, right $(C)$, and left (D) appearance.

Paul Frimpong et al: Incidence and management of mandibular fractures in a low-resource health facility in Ghana. J Korean Assoc Oral Maxillofac Surg 2021 
mated a worldwide male-to-female ratio of $4.43: 1^{1}$. This may be because males are more likely than females to be involved in violence, reckless driving, sports, drugs, and alcohol ${ }^{11}$.

In this study, the most common etiological factor was MVA, representing $75.4 \%$ of the total number of injuries, followed by assault, gunshot, falls, and industrial accidents. There is also a strong difference in the etiology of maxillofacial trauma between low-income and high-income nations. MVAs are more common in low-income nations, while interpersonal violence is more common in high-income countries $^{12}$. Our study supports this conclusion and is consistent with findings from other economically similar countries; e.g., Fasola et al. ${ }^{13}$ and Olayemi et al. ${ }^{14}$ found that MVA was the most common cause of maxillofacial trauma in Nigeria. Further, according to Parkins et al. ${ }^{15}$, MVA was the most common cause of maxillofacial injuries in Ghana. The government of Ghana will therefore need to equip the Motor Traffic and Transport Department of the Ghana Police service to ensure proper enforcement of all road traffic regulations in the country. Furthermore, broader stakeholder consultation needs to be done on the legalization and regulation on the use of motorcycle as means of transportation for commercial activities. Our study found that $55.9 \%$ of cases caused by MVAs occurred at night. Although, no statistical correlation could be drawn between MVAs and the time of the day for its occurrence, further studies need to be con-ducted to determine if there is any scientific correlation for this observation made in our study. Assault was the second most common cause in this study, but this contrasts with some studies of highincome countries that found assault to be the leading cause of maxillofacial injuries, including mandibular fractures ${ }^{16-19}$. On the other hand, a Turkish study found that falls were the main cause of mandible fracture ${ }^{20}$.

In our study, 325 mandibular fractures were recorded in 268 patients with an average of 1.2 fractures per patient: $62.7 \%$ of patients had a single fracture line, $33.2 \%$ had double fracture lines, and $4.1 \%$ had more than two fracture lines. The most frequent location of mandibular fracture lines was in the parasymphyseal region (121/325 fracture lines), which is similar to findings from other studies ${ }^{21-25}$. Data from different countries show large variations in fracture location site. Adebayo et al..$^{26}$ reported the body of the mandible as the most prominent site, while Ragupathy and Pasupathy ${ }^{10}$ and Țenţ et al. ${ }^{27}$ reported the condyle as the most frequent fracture site. In our study, the mandible body was the second most frequent fracture site. Differences in regional and patient factors, etiology, and injury mechanism may contribute to this variation ${ }^{28}$. The most common multiple mandibular fracture recorded in this study involved the parasymphysis and body, followed by the parasymphysis and condyle. This contrasts with a Turkish study that found a combination of parasymphyseal and condylar fractures to be most common ${ }^{29}$, and another study that reported the body and the angle as the most frequent mandibular fracture combination ${ }^{30}$.

The most common associated injury in this study was head injury (39.8\%), followed by maxillary fractures $(20.9 \%)$, which is consistent with findings by Fridrich et al. ${ }^{31}$ and Subhashraj et al. ${ }^{32}$, but differs from Sakr et al..$^{33}$ and Elgehani and $\mathrm{Orafi}^{34}$, who found that maxilla fractures were the most commonly associated injuries due to the bone's proximity to the mandible.

The main goal of mandibular fracture treatment is to achieve anatomical apposition and to restore function. There are many treatment options for maxillofacial fractures, and the choice may differ depending on many factors such as cost, feasibility, doctor's preference and skill, and patient's acceptance of the treatment. Minority of our patients (8.6\%) who were treated with open reduction and internal fixation has severe unfavorable fracture which could not be reduced by closed reduction. The majority of patients treated in our study (79.1\%) received closed reduction with arch bar fixation and few were treated with open reduction and internal fixation, which is consistent with another study ${ }^{5}$. Hill et al. ${ }^{35}$ and Olson et al. ${ }^{36}$ concluded that majority of mandibular fractures are capable of being managed by closed reduction with tolerable clinical result. It is also worth noting that treatment of mandibular fracture can be improved with open reduction and direct fixation to ensure early resumption of jaw function and also reduce long treatment duration which has huge impact on the socio-economic activities of patients.

\section{Conclusion}

Closed reduction with indirect fixation could be used to successfully manage mandibular fractures in low-resource health facilities, especially in low-income countries. Poor lightening systems on roads in Ghana are a major contributory factor to MVAs.

\section{ORCID}

Paul Frimpong, https://orcid.org/0000-0002-1647-2155

Truc Thi Hoang Nguyen, https://orcid.org/0000-00028667-6698 
Buyanbileg Sodnom-Ish, https://orcid.org/0000-00024239-1420

Edinam Salia Nimatu, https://orcid.org/0000-0002-70528738

Nana Yaa Asantewaa Dampare, https://orcid.org/00000002-7423-7938

Roberta Rockson, https://orcid.org/0000-0002-5114-7518

Samuel Baffour Awuah, https://orcid.org/0000-0003-10841316

Emmanuel Kofi Amponsah, https://orcid.org/0000-00020720-3025

Cardinal Newton, https://orcid.org/0000-0001-6084-0173

Soung Min Kim, https://orcid.org/0000-0002-6916-0489

\section{Authors' Contributions}

P.F. participated in data collection and wrote the manuscript. T.T.H.N., B.S-I., E.S.N., N.Y.A.D., R.R., and S.B.A. participated in the study design and performed the statistical analysis. E.K.A. and C.N. participated in the study design and helped to draft the manuscript. S.M.K. coordinated, read and approved the final manuscript.

\section{Acknowledgements}

This study was supported by Basic Science Research Program funded by the Ministry of Education (2017R1D1A1B04029339) and by grant no 03-2019-0043 from the SNUDH Research Fund.

\section{Ethics Approval and Consent to Participate}

The study protocol and access to patient records were approved by the Institutional Review Board of Seoul National University (S-D20200021).

\section{Conflict of Interest}

No potential conflict of interest relevant to this article was reported.

\section{References}

1. Jin KS, Lee H, Sohn JB, Han YS, Jung DU, Sim HY, et al. Fracture patterns and causes in the craniofacial region: an 8-year review of 2076 patients. Maxillofac Plast Reconstr Surg 2018;40:29. https:// doi.org/10.1186/s40902-018-0168-y

2. Abadi M, Pour OB. Genioplasty. Facial Plast Surg 2015;31:513-22. https://doi.org/10.1055/s-0035-1567882

3. Anyanechi CE, Saheeb BD. Mandibular sites prone to fracture: analysis of 174 cases in a Nigerian tertiary hospital. Ghana Med J 2011;45:111-4.

4. Kim SM. Intraoral reinsertion after extracorporeal fixation in condylar fracture. J Korean Assoc Oral Maxillofac Surg 2021;47:4769. https://doi.org/10.5125/jkaoms.2021.47.6.476

5. Shah A, Shah AA, Salam A. Pattern and management of mandibular fractures: a study conducted on 264 patients. Pak Oral Dent J 2007;27:103-6.

6. World Health Organization (WHO). WHO global status report on road safety 2013: supporting a decade of action. Geneva: WHO; 2013.

7. Down KE, Boot DA, Gorman DF. Maxillofacial and associated injuries in severely traumatized patients: implications of a regional survey. Int J Oral Maxillofac Surg 1995;24:409-12. https://doi. org/10.1016/s0901-5027(05)80469-2

8. Ellis E 3rd, Moos KF, el-Attar A. Ten years of mandibular fractures: an analysis of 2,137 cases. Oral Surg Oral Med Oral Pathol 1985;59:120-9. https://doi.org/10.1016/0030-4220(85)90002-7

9. Zhou H, Lv K, Yang R, Li Z, Li Z. Mechanics in the production of mandibular fractures: a clinical, retrospective case-control study. PLoS One 2016;11:e0149553. https://doi.org/10.1371/journal. pone. 0149553

10. Ragupathy K, Pasupathy S. Incidence, aetiology and pattern of mandibular fractures in Pondicherry. J Evol Med Dent Sci 2015;4: 16946.

11. Amin MR, Chowdhury MAP, Sarwar MG, Moula SM, Kabir MH, Ahmed TI, et al. A retrospective study of mandibular fracture in a 2- year period. Bangladesh Dent J 2016;32:1-3.

12. Barde D, Mudhol A, Madan R. Prevalence and pattern of mandibular fracture in Central India. Natl J Maxillofac Surg 2014;5:153-6. https://doi.org/10.4103/0975-5950.154818

13. Fasola AO, Nyako EA, Obiechina AE, Arotiba JT. Trends in the characteristics of maxillofacial fractures in Nigeria. J Oral Maxillofac Surg 2003;61:1140-3. https://doi.org/10.1016/s02782391(03)00671-2

14. Olayemi AB, Adeniyi AO, Samuel U, Emeka OA. Pattern, severity, and management of cranio-maxillofacial soft-tissue injuries in Port Harcourt, Nigeria. J Emerg Trauma Shock 2013;6:235-40. https:// doi.org/10.4103/0974-2700.120362

15. Parkins G, Boamah MO, Avogo D, Ndanu T, Nuamah IK. Maxillofacial and concomitant injuries in multiple injured patients at Korle Bu Teaching Hospital, Ghana. West Afr J Med 2014;33:51-5.

16. Ström C, Nordenram A, Fischer K. Jaw fractures in the County of Kopparberg and Stockholm 1979-1988. A retrospective comparative study of frequency and cause with special reference to assault. Swed Dent J 1991;15:285-9.

17. Layton S, Dickenson AJ, Norris S. Maxillofacial fractures: a study of recurrent victims. Injury 1994;25:523-5. https://doi. org/10.1016/0020-1383(94)90094-9

18. Kheirallah M, Mateńko D. [The epidemiological analysis of mandibular fractures in the material of I Department of Maxillofacial Surgery of Warsaw University in the years 1988-1992]. Czas Stomatol 1994;2:123-7. Polish.

19. Ansari S, Akhdar F, Mandoorah M, Moutaery K. Causes and effects of road traffic accidents in Saudi Arabia. Public Health 2000; 114:37-9. https://doi.org/10.1038/sj.ph.1900610

20. Bereket C, Şener İ, Şenel E, Özkan N, Yilmaz N. Incidence of mandibular fractures in black sea region of Turkey. J Clin Exp Dent 2015;7:e410-3. https://doi.org/10.4317/jced.52169

21. Ravindran V, Ravindran Nair KS. Metaanalysis of maxillofacial trauma in the northern districts of Kerala: one year prospective study. J Maxillofac Oral Surg 2011;10:321-7. https://doi. org/10.1007/s12663-011-0264-3

22. Natu SS, Pradhan H, Gupta H, Alam S, Gupta S, Pradhan R, et al. An epidemiological study on pattern and incidence of man- 
dibular fractures. Plast Surg Int 2012;2012:834364. https://doi. org $/ 10.1155 / 2012 / 834364$

23. King RE, Scianna JM, Petruzzelli GJ. Mandible fracture patterns: a suburban trauma center experience. Am J Otolaryngol 2004;25:301-7. https://doi.org/10.1016/j.amjoto.2004.03.001

24. Atanasov DT. A retrospective study of 3326 mandibular fractures in 2252 patients. Folia Med (Plovdiv) 2003;45:38-42.

25. Wong KH. Mandible fractures: a 3-year retrospective study of cases seen in an oral surgical unit in Singapore. Singapore Dent J 2000;23(1 Suppl):6-10.

26. Adebayo ET, Ajike OS, Adekeye EO. Analysis of the pattern of maxillofacial fractures in Kaduna, Nigeria. Br J Oral Maxillofac Surg 2003;41:396-400. https://doi.org/10.1016/s02664356(03)00165-7

27. Țenţ PA, Popa D, Juncar RI, Haranguş A, Lung T, Juncar M, et al. The pattern and characteristics of mandibular fractures - a 3-year prospective clinical study. ASRJETS 2017;32:168-80.

28. Motamedi MH, Dadgar E, Ebrahimi A, Shirani G, Haghighat A, Jamalpour MR. Pattern of maxillofacial fractures: a 5-year analysis of 8,818 patients. J Trauma Acute Care Surg 2014;77:630-4. https://doi.org/10.1097/TA.000000000000369

29. Rix L, Stevenson AR, Punnia-Moorthy A. An analysis of 80 cases of mandibular fractures treated with miniplate osteosynthesis. Int J Oral Maxillofac Surg 1991;20:337-41. https://doi.org/10.1016/ s0901-5027(05)80261-9

30. Ogundare BO, Bonnick A, Bayley N. Pattern of mandibular fractures in an urban major trauma center. J Oral Maxillofac Surg 2003;61:713-8. https://doi.org/10.1053/joms.2003.50118

31. Fridrich KL, Pena-Velasco G, Olson RA. Changing trends with mandibular fractures: a review of 1,067 cases. J Oral Maxillofac Surg 1992;50:586-9. https://doi.org/10.1016/0278-2391(92)90438-6

32. Subhashraj K, Nandakumar N, Ravindran C. Review of maxillofacial injuries in Chennai, India: a study of 2748 cases. Br J Oral Maxillofac Surg 2007;45:637-9. https://doi.org/10.1016/ j.bjoms.2007.03.012

33. Sakr K, Farag IA, Zeitoun IM. Review of 509 mandibular fractures treated at the University Hospital, Alexandria, Egypt. Br J Oral Maxillofac Surg 2006;44:107-11. https://doi.org/10.1016/ j.bjoms.2005.03.014

34. Elgehani RA, Orafi MI. Incidence of mandibular fractures in Eastern part of Libya. Med Oral Patol Oral Cir Bucal 2009;14:e529-32. https://doi.org/10.4317/medoral.14.e529

35. Hill CM, Crosher RF, Carroll MJ, Mason DA. Facial fractures-the results of a prospective four-year-study. J Maxillofac Surg 1984;12:267-70. https://doi.org/10.1016/s0301-0503(84)80257-x

36. Olson RA, Fonseca RJ, Zeitler DL, Osbon DB. Fractures of the mandible: a review of 580 cases. J Oral Maxillofac Surg 1982;40: 23-8. https://doi.org/10.1016/s0278-2391(82)80011-6

How to cite this article: Frimpong P, Nguyen TTH, SodnomIsh B, Nimatu ES, Dampare NYA, Rockson R, et al. Incidence and management of mandibular fractures in a low-resource health facility in Ghana. J Korean Assoc Oral Maxillofac Surg 2021;47:432-437. https://doi.org/10.5125/jkaoms.2021.47.6.432 